\title{
Chest radiology in cystic fibrosis: is scoring useful?
}

With the increasing survival in patients with cystic fibrosis and the primary cause of death in older patients being due to respiratory disease, there is renewed interest in the formalised scoring of chest radiographs. ${ }^{1}$ Scoring systems have developed as part of an overall clinical assessment ${ }^{2-4}$ and as specific staging scores for respiratory disease. ${ }^{5-8}$ Most have been devised for use with children but are often applied to adult patients. There has been only a limited evaluation of reproducibility and reliability of such scores and of their relation to other indicators of the extent of lung disease. There is therefore a need to question their value in clinical practice and research, and in the context of newer imaging techniques. In this issue of Thorax two papers are published that compare the main scoring methods and describe a new scoring system..$^{910}$

The earliest radiographic changes indicating lung disease in cystic fibrosis are overinflation or atelectasis, probably related to mucus plugging. With progression from a bronchiolitis to bronchitis, bronchial wall thickening occurs giving radiographic circular lesions or tramlines depending on the orientation of the bronchi to the $x$ ray beam. Progressive bronchiectasis is associated with the appearance of cysts and rounded opacities, depending on their content of mucopus, which may coalesce into large lesions. Fibrotic changes may cause a generalised increase in background shadowing on the radiograph. Previous scoring systems have rated the severity or extent of such changes and have been used both to monitor management and to define severity of lung disease for research purposes. With the widespread changes present in the lungs of adult patients scoring systems may be less sensitive, although many centres still use them as part of an annual assessment of their patients.

Conway et al ${ }^{9}$ (pp 860-2) report a new system based on a straightforward assessment of a posteroanterior chest radiograph by a single observer. The merits of this method are simplicity, rapidity, and results comparable with other currently used systems. In a separate comparison, also involving the Brasfield method, three methods were shown by Sawyer et al $^{10}$ (pp 863-6) to vary in repeatability and to have only a modest relation to spirometry, indicating that much of the variability in scores was not related to spirometric indicators of lung disease. ${ }^{10}$

The inherent weakness of radiographic scoring systems is the lack of relation of plain radiographic changes to the pathological process occurring in the lungs. High resolution computed axial tomography can clarify and extend changes demonstrated on the plain radiograph ${ }^{112}$ by showing both the distribution and severity of bronchiectasis. Changes demonstrated by computed tomographic scanning relate more to the understood pathology (for example, mucus plugging, consolidation, bronchiectasis and bronchial wall thickening) than to linear shadows, cysts, or nodularity which are noted in chest radiograph scores. Computed tomographic scanning will often demonstrate early involvement of the lungs at a time when the chest radiograph may appear to be normal. However, computed tomographic scanning involves considerably greater exposure to radiation than a series of chest radiographs over 10-20 years. It is interesting that scoring systems have also been developed for the computed tomographic scan, based on specific changes, but are not currently in routine usage. ${ }^{12}$

It is likely that scoring systems for the chest radiograph will continue to be used by physicians and, with some refinements, may be of value in the assessment of the clinical status of both paediatric and adult patients with cystic fibrosis. The application to research of such scores may be less useful and computed tomographic assessment may have a role here.

Section of Respiratory Medicine,

D J SHALE

University of Wales College of Medicine,

Llandough Hospital,

Penarth,

South Glamorgan CF6 $1 \mathrm{XX}$,

$U K$

1 Elborn JS, Shale DJ, Britton JR. Cystic fibrosis: population predictions until the year 2000. Thorax 1991;46:881-5.

2 Schwachman H, Kulczycki LL. Long-term study of 105 patients with cystic fibrosis. F Dis Child 1958;96:6-15.

3 Doershuk CF, Matthews LW, Tucker AS, Nudelman H, Eddy G, Wise M, et al. A 5 year clinical evaluation of a therapeutic program for patients with cystic fibrosis. F Pediatr 1964;65:677-93.

4 Taussig LM, Kattwinkel J, Friedewald WT, di Sant'Agnese PA. A new prognostic score and clinical evaluation system for cystic fibrosis. $\mathcal{F}$ Pediatr 1973;82:380-90.

5 Chrispin A, Norman A. The systematic evaluation of the chest radiograph in cystic fibrosis. Pediatr Radiol 1974;2:101-6.

6 Brasfield D, Hicks G, Soong S-J, Tiller RE. The chest roentgenogram in cystic fibrosis. A new scoring system. Pediatrics 1979;63:24-9.

Cooperman EM, Park M, MeKee J, Assad JP. A simplified cystic fibrosis scoring system (a preliminary report). Can Med Assoc F 1971;105:580-2. scoring system (a preliminary report). Can Med Assoc 7 1971;105:580-2.
Holzer FJ, Olinsky A, Phelan PD. Variability of airways hyper-reactivity Holzer FJ, Olinsky A, Phelan PD. Variability of airways hyp
and allergy in cystic fibrosis. Arch Dis Child 1981;56:455-9.

9 Conway SP, Pond MN, Bowler I, Smith DL, Simmonds EJ, Joanes DN, et al. The chest radiograph in cystic fibrosis: a new scoring system compared with the Chrispin-Norman and Brasfield scores. Thorax 1994 49:860-2.

10 Sawyer SM, Carlin JB, DeCampo M, Bowes G. Critical evaluation of three chest radiograph scores in cystic fibrosis. Thorax 1994;49:863-6.

11 Lynch DA, Brasch RC, Hardy MKA, Webb WR. Pediatric pulmonary disease: assessment with high resolution ultrafast CT. Radiology 1990 176:243-8.

12 Bhalla M, Turcios NM, Aponte V, Jenkins M, Leitman BS, McCauley DI, et al. Cystic fibrosis: scoring system with thin-section. Radiology 1991; 179:783-8. 